\title{
The Risk Study and Control in Investment Decision
}

\author{
Jun Li \\ Management School, Wuyi University, Jiangmen, Guangdong 529020, China \\ E-mail: junlzx@126.com \\ Yanbin Sun \\ Management School of Daqing Petroleum Institute, Daqing 163318, China
}

\begin{abstract}
We give the descriptions of the concepts of investment and risk related to investment first. Then, we consider how to measure the rates of return and the risk for alternative investments, and what factors determine an investor's required rate of return on an investment in the second section. In order to control the risk systematically, the portfolio control process is proposed in section 3. Section 4 describes in detail the three major composite equity portfolio performance measures that combine risk and return performance into a single value. We describe each measure and its intent, and then demonstrate how to compute it and interpret the results. We also compare two of the measures and discuss how they differ and why they rank portfolios differently. The real application on the risk study and control in investment is discussed at the end.
\end{abstract}

Keywords: Investment, Risk Control, Modeling, Decision Making, Portfolio

\section{Introduction}

With the progress of global economy and the development of information technology, Investment Analysis and Management (IAM) is becoming more and more important in enterprise strategy management. An important purpose of the IAM is to help an entity to integrate information from a variety of sources and to integrate their efforts to solve the global investment problem. The information resources, which many include databases, decision models and knowledge bases, will be shared by several users, many of them responsible for one aspect of an overall decision problem. Modeling and analyzing is the corn of the IAM and the research on the investment risk and return is the first thing to deal.

This section discusses several topics that are basic to subsequent sections. We begin with a consideration of what are investment and the risks related to investment. This leads to a presentation of how to measure the expected and historical rates of return for an individual asset or a portfolio of assets. In addition, we consider how to measure the risk not only for an individual investment, but also for an investment that is part of a portfolio.

Specifically, an investment is the current commitment of dollars for a period of time to derive future payments that will compensate the investor for the time the funds are committed, the expected rate of inflation, and the uncertainty of the future payments (Aswath, 1999). In all cases, the investor is trading a known dollar amount today for some expected future stream of payments that will be greater than the current outlay. At this point, Risk is the uncertainty that an investment will earn its expected rate of return. Risk, in traditional terms, is viewed as a "negative." Webster's dictionary, for instance, defines risk as "exposing to danger or hazard." The Chinese symbols for risk, reproduced below, give a much better description of risk: the first symbol is for "danger," while the second symbol is for "opportunity," making risk a mix of danger and opportunity. It illustrates very clearly the tradeoff that every investor and business has to make between the "higher rewards" that potentially come with the opportunity and the "higher risk" that has to be borne as a consequence of the danger. The key test in finance is to ensure that when an investor is exposed to risk he or she is "appropriately" rewarded for taking this risk.

\section{The Models for Measuring Risk}

In this section, we shall lay the foundations for analyzing risk in corporate finance and present alternative models for measuring risk and converting these risk measures into "acceptable" hurdle rates.

\subsection{A Relative measure of risk}

We can calculate the expected rate of return and evaluate the uncertainly, or risk, of an investment by identifying the range of possible returns from that investment and assigning each possible return a weight based on the probability that it will occur. A relative measure of risk that is widely used is the Coefficient of Variation, which is equal to $C V=\frac{\sigma}{E(R)}$. Where $C V$ expresses Coefficient of Variation, $\sigma$ is the Standard Deviation of Returns, and $E(R)$ means the Expected Rate of Return. 


\subsection{Required Rate of Return (RRR)}

We continue our consideration of factors that must consider when selecting securities for an investment portfolio. Required rate of return is the minimum rate of return that you should accept from an investment to compensate you for deferring consumption. Because differences in yields result from the risk of each investment, you must understand the risk factors that affect the required rate of return and include them in your assessment of investment opportunities. Figure 1 graphs the expected relationship between risk and return.

RFR (Risk-free Rate) is the basic interest rate, assuming no inflation and no uncertainty about future flows. The risk-free rate of interest is the price charged for the certain exchange between current goods and future goods. Two factors, one subjective and one objective, influence this exchange price. The subjective factor is the time preference of individuals for the consumption of income. The objective factor that influences the risk-free rate is the set of investment opportunities available in the economy. The investment opportunities are determined in turn by the long-run real growth rate of the economy. A positive relationship exists between the real growth rate in the economy and the RFR.

Most investors require higher rates of return on investments to compensate for any uncertainty. The slope of the security market line indicates the return per unit of risk required by all investors. Assuming a straight line, it is possible to select any point on the SML and compute RRR through the RP (Risk Premium). The equation is $R R R=R F R+R P$.

Although the required risk premium represents a composite of all uncertainty, it is possible to consider several fundamental sources of uncertainty. The major sources include business risk, financial risk, liquidity risk, exchange rate risk, and country risk.

\subsection{Regression Model}

The model above begins by thinking about market in broad intuitive terms and then developing economic model that might best explain this market risk. The regression model try to explain differences in returns across long time periods using firm characteristics such as the size of the firm and its price multiples. The firm characteristics that best explain differences in returns can be viewed as effective proxies for market risk.

Fama and French (Fama and French, 1992, pp. 427-466), in a highly influential study of the capital asset pricing model in the early 1990's, note that actual return on firms over long time periods have been highly correlated with their price/book value ratios and their market capitalization. They suggest that these measures, and similar ones developed from the data, be used as proxies for risk and that the regression coefficients be used to estimate required returns for investments. For instance, Fama and French report the following regression for monthly returns on stocks on the NYSE, using data from 1963 to 1990 :

$$
R R R=1.77 \%-0.11 \ln (M V)+0.35 \ln (B V / M V)
$$

Where $M V$ is the Market value of equity, $B V$ means the Book value of equity (in million). The values for $M V$ and $B V / M V$ for individual firm should yield required monthly returns when them plugged into the regression.

\section{The Portfolio Control Process}

The first step in the portfolio control, as seen in Figure 2, is for the investor to construct a policy statement. The policy statement specifies the types of risks the investor is willing to take and his or her investment goals and constraints. Since investor needs change over time, the policy statement must be periodically reviewed and updated(Frank and Brown, 1997. Bhatia, 1990)

In the second step of the portfolio control process, the investor studies current financial and economic conditions and attempts to forecast future trends. Because economies are dynamic, the portfolio will have to be constantly monitored and updated to include asset reallocations to reflect changes in financial market expectations.

The third step of the portfolio control process is to construct the portfolio. This involves constructing a portfolio that will minimize the investor's risks while meeting the return needs specified in the policy statement.

The fourth step of the portfolio control process is to continually monitor the investor's needs and capital market conditions. When necessary, an updated policy statement is written and the investment strategy is modified accordingly. A component of the monitoring process is to evaluate a portfolio's performance and compare the results to the expectations and requirements as specified in the policy statement. The evaluation of portfolio performance is discussed in the section 4 .

\section{The Evaluation of Performance}

At one time, investors evaluated portfolio performance almost entirely on the basis of the rate of return. They were 
aware of the concept of risk, but did not know how to quantify or measure it, so they could not consider it explicitly. Developments in portfolio theory in the early 1960's showed investors how to quantify and measure risk in terms of the variability of returns. Still, because no single measure combined both return and risk before 1960's, the two factors had to be considered separately as researcher had done in several early studies (Irwin, Marshall, and Jean, 1970).

This section describes in detail the three major composite equity portfolio performance measures that combine risk and return performance into a single value. We describe each measure and its intent, and then demonstrate how to compute it and interpret the results. We also compare two of the measures and discuss how they differ and why they rank portfolios differently.

\subsection{The Systematic Risk Measure}

Building on developments in capital market theory, a risk-free asset, which could be combined with different portfolios to form a straight portfolio possibility line, was introduced by Treynor (Jack L, 1965, pp. 63-75). The rational, risk-averse investors would always prefer portfolio possibility lines with larger slopes because such high-slope lines would place investors on higher indifference curves. The slope of this portfolio possibility line (designated $S$ ) is equal to:

$$
S=\frac{\overline{R R}_{i}-\overline{R F R}}{\beta_{i}} .
$$

Where $\overline{R R}_{i}$ is the average rate of return for portfolio $i$ during a specified period, $\overline{R F R}$ is the average rate of return on a risk-free during the same period, and $\beta_{i}$ is the slope of the fund's characteristic line.

As noted, a larger $S$ value indicates a larger slope and a better portfolio for all investors (regardless of their risk preferences). It indicates the portfolio's risk premium return per unit of risk. Note that the risk variable beta measures systematic risk and tells us nothing about the diversification of the portfolio. It implicitly assumes a completely diversified portfolio, which means that systematic risk is the relevant risk measure.

Comparing a portfolio's $S$ value to a similar measure for the market portfolio indicates whether the portfolio would plot above the SML. Calculate the $S$ value for the aggregate market as follows:

$$
S_{m}=\frac{\overline{R R}_{m}-\overline{R F R}}{\beta_{m}} .
$$

In this expression, $\beta_{m}$ equals 1.0 (the market's beta) and indicates the slope of the SML. Therefore, a portfolio with a higher $S$ value than the market portfolio plots above the SML, indicating superior risk-adjusted performance.

Figure 3 is showing that portfolio $X$ not only ranked the lowest of the three portfolios, but did not perform as well as the aggregate market. In contrast, both $Y$ and $Z$ beat the market portfolio, and $Z$ performed somewhat better than $Y$.

\subsection{The standard deviation Measure}

The measure (Frank and Brown, 1997) of portfolio performance is stated as $S=\frac{\overline{R R}-\overline{R F R}}{\sigma_{i}}$. This composite measure of portfolio performance clearly is similar to the first one; however, it seeks to measure the total risk of the portfolio by including the standard deviation of returns rather than considering only the systematic risk summarized by beta. Because the numerator is the portfolio's risk premium, this measure indicates the risk premium return earned per unit of total risk. In terms of capital market theory, this portfolio performance measure uses total risk to compare portfolios to the capital market line (CML).

Figure 4 is showing that portfolio $X$ had the lowest risk premium return per unit of total risk, failing even to perform as well as the aggregate market. In contrast, both $Y$ and $Z$ performed better than the aggregate market. The portfolio $Y$ did better than portfolio $Z$.

\subsection{The Expected Return Measure}

The measure (Frank and Brown, 1997) of portfolio performance is stated as $E\left(R_{j}\right)=R F R+\beta_{j}\left[E\left(R_{m}\right)-R F R\right]$. Where $E\left(R_{j}\right)$ means the expected return on security or portfolio $j, \beta_{j}$ is the systematic risk (beta) for security or portfolio $j, E\left(R_{m}\right)$ is the expected return on the market portfolio of risky assets. The expected return and the risk-free return vary for different periods. Consequently, we are concerned with the time series of expected rates of return for security or portfolio $j$. Moreover, assuming the asset-pricing model is empirically valid, you can express the expectations formula in terms of realized rates of return as follows: 


$$
R_{j t}=R F R_{t}+\beta_{j}\left[R_{m t}-R F R_{t}\right]+U_{j t} .
$$

This equation states that the realized rate of return on a security or portfolio during a given period should be a linear function of the risk-free rate of return during the same period, plus a risk premium that depends on the systematic risk of the security or portfolio during the period plus a random error term. Subtracting the risk-free return from both sides, we have

$$
R_{j t}-R F R_{t}=\beta_{j}\left[R_{m t}-R F R_{t}\right]+U_{j t} .
$$

This shows that the risk premium earned on the $j$ th portfolio is equal to $\beta_{j}$ times a market risk premium plus a random error term. In this form, an intercept for the regression is not expected if all assets and portfolio were in equilibrium.

Alternatively, superior portfolio manager who forecast market turns or consistently select undervalued securities earn higher risk premiums than those implied by this model. To detect and measure this superior performance, you have to allow for an intercept (a nonzero constant) that measures any positive or negative difference from the model. With an intercept or nonzero constant, the earlier equation becomes

$$
R_{j t}-R F R_{t}=\alpha_{j}+\beta_{j}\left[R_{m t}-R F R_{t}\right]+U_{j t} .
$$

In this equation, the $\alpha_{j}$ value indicates whether the portfolio manager is superior or inferior in market timing and /or stock selection. Therefore, the $\alpha_{j}$ value represents how much of the rate of return on the portfolio is attributable to the manager's ability to derive above-average return adjusted for risk. Superior risk-adjusted returns indicate that the manager is good at either predicting market turns, or selecting undervalued issues for the portfolio, or both.

All of the performance measures just described are only as good as their data inputs. You must be careful when computing the rates of return to take proper account of all inflows and outflows. Theoretically, the market portfolio is an efficient, completely diversified portfolio because it is on the efficient frontier. We also noted that this market portfolio must contain all risky assets in the economy, so that it will be completely diversified, and that all components are market value weighted. The problem arises in finding a realistic proxy for this theoretical market portfolio. While the Standard \& Poor's 500 Index is used as the proxy in practice, but it does not represent the true composition of the market portfolio. Specifically, it includes only common stocks and most of them are listed on the NYSE. This lack of completeness, known as a benchmark error, is highlighted with global investing. Several points are significant regarding this benchmark criticism. First, the benchmark problems do not negate the value of the capital asset pricing model (CAPM) as a normative model of equilibrium pricing; the theory is still viable. The problem is one of measurement when using the theory to evaluate portfolio performance. You need to find a better proxy for the market portfolio or to adjust measured performance for benchmark errors. In fact, Roll made several suggestions to help overcome this problem (Richard, 1981. pp. 17-22). Alternatively, you might consider giving greater weight to the standard deviation measure because it does not depend heavily on the market portfolio.

In summary, because of a growing desire to evaluate aggregate performance and identify what factors contribute to superior or inferior performance, benchmark must be selected at two levels: a global level that contains the broadest mix of risky assets available from around the world and a fairly specific level consistent with the management style of an individual money manager.

\section{References}

Aswath Damodaran. (1999). Applied Corporate Finance. John Wiley \& Sons, Inc..

Bhatia and Sanjiv. (1990). Management Assets for Individual Investors. Charlottesville. VA: Association for Investment Management and Research.

Fama, E. F. and K. R. French. (1992). The Cross-Section of Expected Returns. Journal of Finance. Vol.47 p.427-466.

Frank K. R. and K. C. Brown. (1997). Investment Analysis and Portfolio Management. The Dryden Press.

Irwin Friend, Marshall Blume, and Jean Crockett. (1970). Mutual Funds and Other Institutional Investors. New York: McGraw-Hill.

Jack L. Treynor. (1965). How to Rate Management of Investment Funds. Harvard Business Review 43. No. 1. p.63-75.

Jeffrey V. Bailey. (1992). Are Manager Universes Acceptable performance Benchmarks? Journal of Portfolio Management. Vol. 18. No. 3. p.9-13. 
Richard C. Grinwold. (1992). Are Benchmark Portfolios Efficient? Journal of Portfolio Management. Vol. 19. No. 1.p.34-40.

Richard Roll. (1981). Performance Evaluation and Benchmark ErrorII. Journal of Portfolio Management. Vol. 7. No. 2.p.17-22.

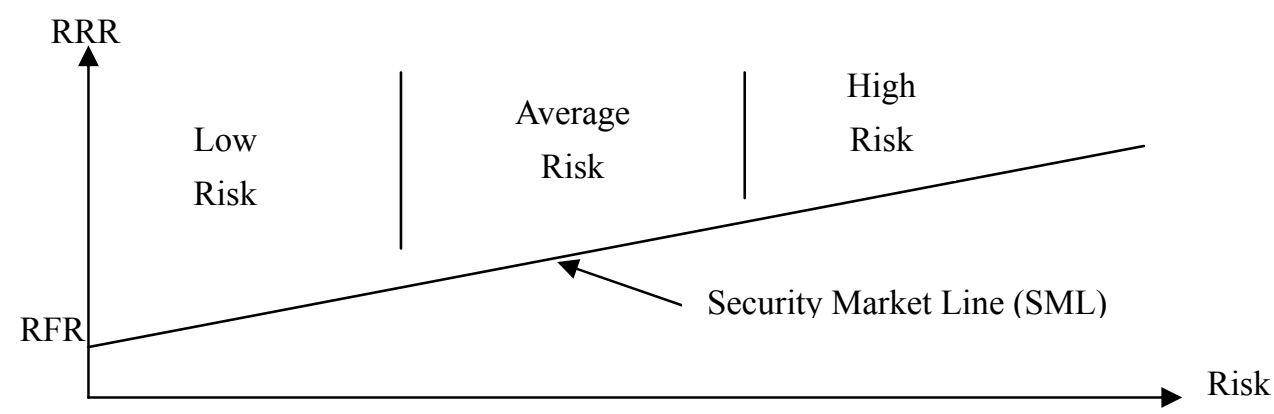

Figure 1. Relationship Between Risk and Return

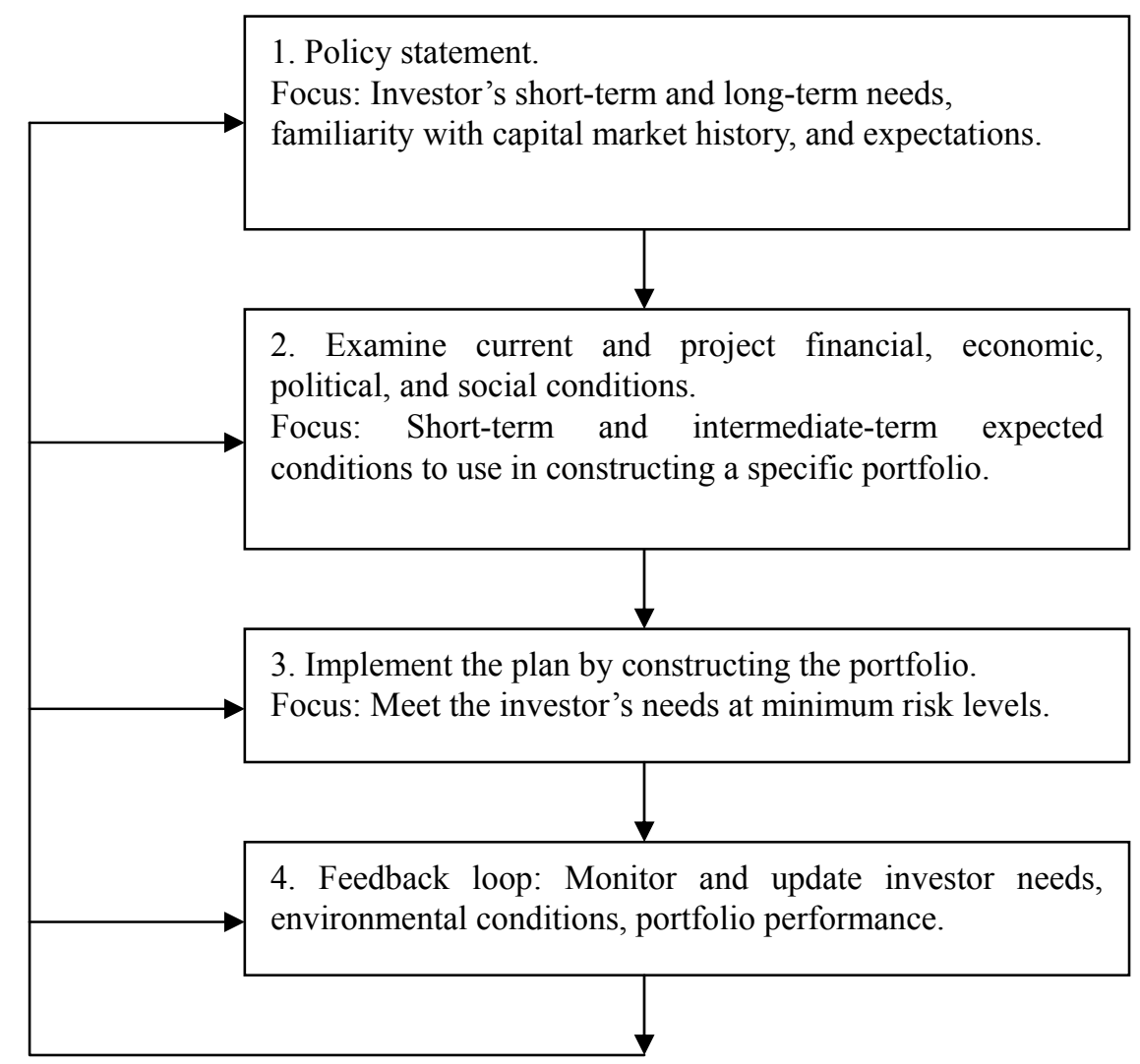

Figure 2. The Portfolio Control Process 


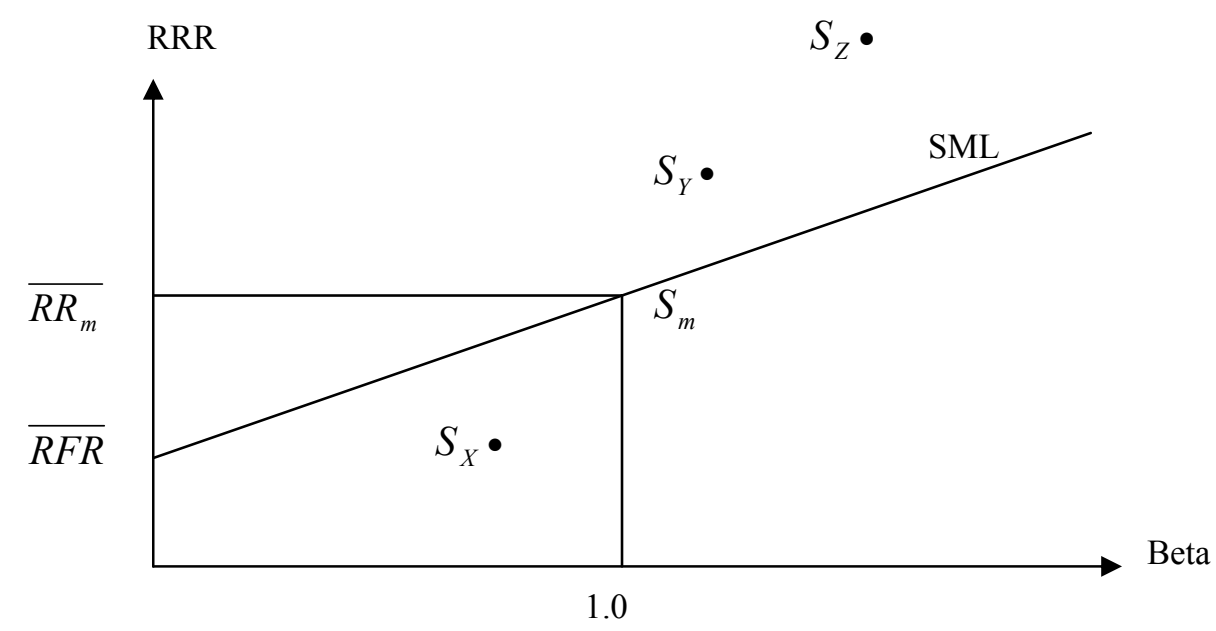

Figure 3. Plot of Performance on SML

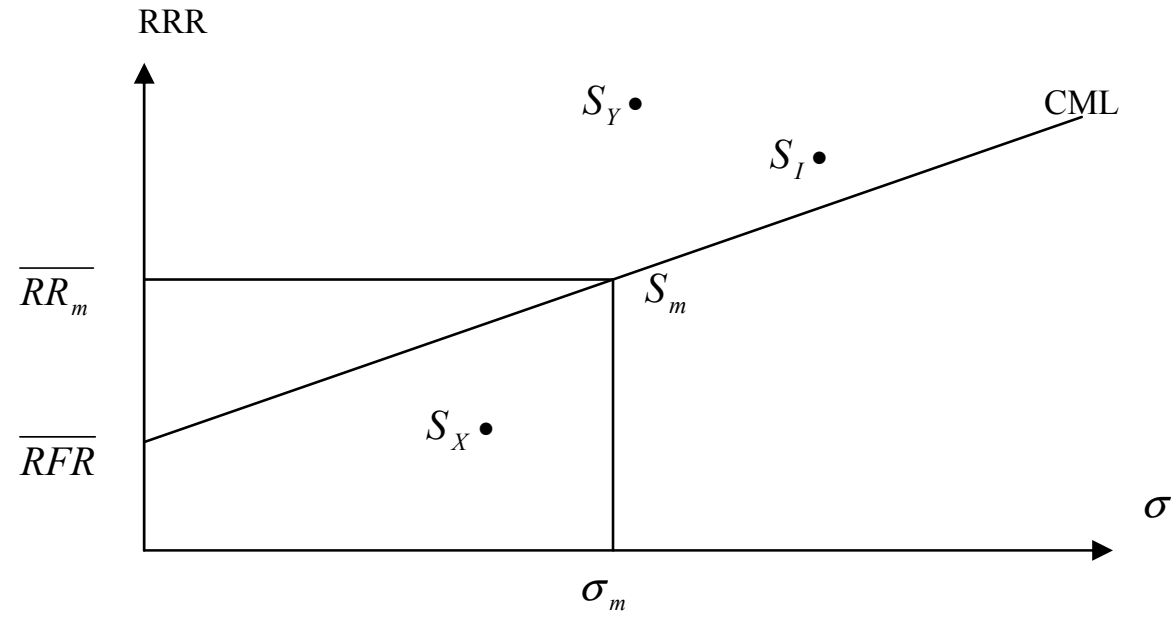

Figure 4. Plot of Performance On CML 